\title{
DOCUMENTOS
}

\section{[LA BÚSQUEDA DE LA VERDAD Y LA EXCELENCIA ACADÉMICA: Reflexiones sobre el Proceso de Evaluación Académica en la Universidad de Chile]}

Prof. Dr. Mario Sapag-Hagar

Presidente de la Comisión Superior de Evaluación

de la Universidad de Chile (1991 - 1998)

\section{RESUMEN}

Cuando Platón regresó a Atenas en el año 387 a.C., estableció una escuela de filosofía en un jardín, a poco más de $1 \mathrm{Km}$. de distancia de la ciudad, con olivos, estatuas y templos, denominado Academos, en honor a su primitivo propietario el legendario héroe del Atica. Esta Academia de Platón perduraría durante novecientos años como centro de la vida intelectual griega y llegaría a constituirse en la precursora del pensamiento universitario de hoy al que transmitiría su virtud, sus herramientas, su fuerza y su misión. Misión de transmitir el saber a través de la docencia, de crear conocimiento y formas nuevas mediante la investigación científica y artística y, por último, de transmitir la cultura o sea, como dice Ortega, aquel sistema de ideas vivas que cada tiempo posee y desde las cuales el tiempo vive.

Es asombroso comprobar cómo estos principios se han mantenido intactos e impertérritos ante el tiempo que todo lo desgasta. Es que un hálito de eternidad flota etéreo e inmutable en este mundo de las ideas y del espíritu.

La vida académica, entendida como una comunidad de estudio, de aprendizaje e investigación, sólo puede ser concebida en un ambiente de plena libertad y de exigente entrega a la verdad. Verdad que no sólo estamos obligados a extraer de las cosas que nos ocupan, sino también de aquellos que la buscan. Es la verdad de la obra realizada, su excelencia y trascendencia, las que permiten, tras un proceso normado de evaluación académica, justipreciar el reconocimiento que le corresponde a cada cual y asignarle la responsabilidad que cabe confiarle en la tarea universitaria. La evaluación académica es un instrumento esencial para la vida y estructura de la Universidad y, sin duda, para su futuro. La generación de autoridades competentes, la asignación de responsabilidades, los derechos políticos de los académicos en el manejo de la Institución, e incluso sus rentas, dependen de la evaluación académica. Es decir, que el proceso en cuestión tiene proyecciones que van más allá de la sola decisión de ingreso, promoción y permanencia en una determinada jerarquía a nivel académico.

El hombre, decía Protágoras, es la medida de todas las cosas por lo que, a su vez, es la medida de la ciencia, de la cultura y de la Universidad misma. Es el 
hombre el que hace la vida espiritual, fundamento de la Universidad.

\section{Docencia, ciencia, técnica y humanismo}

La docencia, junto a la investigación científica, técnica y humanística, se constituyen en la esencia misma de la Universidad, y, por lo mismo, en parte fundamental del proceso de evaluación académica. Cabe, pues, hacer algunas breves consideraciones al respecto:

Las Universidades son por su esencia e historia, instituciones de educación superior de la inteligencia que contribuyen al desarrollo nacional entregando a la comunidad personas poseedoras de creatividad, espíritu crítico, capacidad de análisis y preparadas para resolver con eficacia los complejos problemas de la realidad contingente.

Una Universidad que no desarrolla la imaginación de sus estudiantes, que no les provoca el entusiasmo, ni les proporciona los métodos para seguir adelante, no cumple con su misión esencial. La docencia merece, por ello, no sólo una cuidadosa planificación general y apoyo para alcanzar estos objetivos fundamentales, sino también que se la estimule y oriente con una adecuada evaluación cualitativa de aquellos que la ejercen. La Comisión Superior de Evaluación ha elaborado una pauta orientadora y consensual que facilite la evaluación de la docencia, tanto de pre como de postgrado.

En relación a la investigación, ésta actualmente está alcanzando un papel dominante en la vida universitaria, al punto de que, en los países más avanzados, la contratación del profesorado universitario se guía de manera importante por la excelencia investigadora de los candidatos. Esta importantísima presencia de la investigación en las actividades académicas de la universidad moderna tiene lugar en un momento histórico en el que la revolución científicotécnica está actuando como motor de crecimiento en los países más desarrollados. La sociedad está generalmente interesada en problemas concretos que, en última instancia, han de ser resueltos por la ciencia aplicada. Sin embargo, la investigación aplicada no es posible sin el marco conceptual y analítico que proporciona la ciencia básica. Muchas empresas y universidades privadas no entienden esto. Desean la punta del iceberg, pensando que se puede prescindir de la parte básica que permanece sumergida.

Esta tendencia a la subvaloración privada de la investigación fundamental se ve reforzada porque, en la actualidad, este tipo de investigación es cara y sus resultados son a largo plazo y prácticamente imposibles de patentar. Por esto, la investigación básica o fundamental es preponderantemente promovida en todos los países por el Estado, particularmente a través de las universidades públicas. Presionar a las universidades, más allá de una razonable interacción enriquecedora entre sus investigaciones y las de las empresas, a fin de generar desarrollos tecnológicos susceptibles de aplicación rápida y directa, puede llevar 
no sólo a menoscabar la investigación básica universitaria sino que también llegar a generar una confusión peligrosa respecto a su misión esencial con riesgo de desnaturalizar la actividad propia de la universidad. Aquí cabe, pues, buscar un adecuado equilibrio.

Las humanidades, por otra parte, y al igual que en el pasado, deben continuar siendo una parte fundamental de nuestra cultura y del quehacer de la universidad para evitar caer en un tecnicismo bárbaro e inmovilizador. La historia, la literatura, la moral, la filosofía, el derecho, las artes, constitutivas todas de la ciencia del hombre, son la esperanza para el bienestar moral y social del mundo y de la supervivencia democrática de los valores de la libertad y autonomía de la persona humana. Son ellas las que nos esclarecen la posición del hombre en el cosmos, su dirección, el ocaso de situaciones históricas y el alba de otras nuevas. Sus enseñanzas son extraordinariamente útiles para no insistir en graves errores del pasado.

Hemos tomado conciencia de que el conocimiento en sí es una forma de creación, pero la tecnología y el arte también lo son. ¿Y qué valor concede el proceso evaluador universitario a las contribuciones tecnológicas y artísticas frente a las aportadas por el conocimiento básico? Para analizar esta pregunta, tan socorridamente formulada a las Comisiones de Evaluación Académica, los invito a contemplar un detalle del fresco de Rafael que se conserva en El Vaticano titulado "La Escuela de Atenas", por muchos también conocido como "La Academia de Platón": Platón y Aristóteles caminan hacia nosotros, la mano de Platón apunta hacia los cielos y la de Aristóteles hacia el plano de la tierra.

El mudo mensaje de tan soberbia pintura es consistente con los respectivos enfoques filosóficos de sus dos protagonistas en la búsqueda del conocimiento. Platón busca el ideal, en tanto que Aristóteles mira hacia los objetos y formas de la naturaleza. La pregunta que debemos hacernos en este dualismo que oscila entre la idea y el objeto es: ¿debemos seguir la dirección de la mano de Platón o la de Aristóteles?. El desarrollo de la civilización occidental terminó exigiendo que el idealismo de Platón y el realismo de Aristóteles se fundieran como resultado de la insaciable curiosidad del hombre por explorar lo desconocido y contribuir al bienestar de la humanidad a través del dominio de la naturaleza y del gobierno del mundo para ponerlo a su servicio.

Empezamos, así, a entender que esa dignidad que veía el hombre de la antigüedad en el conocimiento mismo, en ese mundo idealista de las ideas a que apuntara Platón, puede ser extendida o trasladada al mundo de los objetos, al realismo de Aristóteles. El conocimiento básico condujo a la técnica y la técnica ha permitido el dominio humano del entorno y amplificado su poder y alcance para conocer, generando así más conocimiento básico. La creatividad tecnológica debe, por lo mismo, ser evaluada con igual respeto en su intrínseca originalidad y proyección humana. El hombre se ha convertido, a semejanza de la naturaleza misma, en un notable creador de formas y materiales nuevos. 
Técnica, Ciencia y Arte son, sin duda, los tres resultados capitales de la relación del académico con el mundo en que existe y a la ponderación de ellos tres se dedican los evaluadores con igual respeto, objetividad y dedicación aún cuando con diferente grado de dificultad. La Técnica es dominio de la naturaleza, la Ciencia es amor de intelección, es decir de conocimiento del mundo sin su modificación utilitaria ni dominio del mismo. En cambio, actuando por el camino del arte lo que impulsa al hombre, según Laín Entralgo, es un amor de perfección, es decir su voluntad de perfeccionar de una u otra manera, imitando o recreando, lo que en el mundo ve. Más allá del mito y de la especulación ingenua los griegos entrevieron la verdad: el hombre es la medida de todas las cosas y el mundo que él posee es el que él mismo se construye con sus propios proyectos. Es a él, a su espíritu creador, comprometido y generoso, al que apunta la selección académica.

Esta última es la principal labor de la Comisión Superior de Evaluación Académica de nuestra Universidad, a la cual se le han encomendado dos obligaciones esenciales: por una parte ratificar las resoluciones de las Comisiones de Evaluación de Facultades e Institutos Interdisciplinarios referentes a las dos más altas jerarquías académicas, las de profesores titular y asociado y, por otra, resolver las apelaciones de los académicos con respecto a la evaluación que de ellos han hecho las Comisiones de Facultades e Institutos.

El Reglamento General de Carrera Académica, acordado por el Consejo Universitario a través del Decreto Universitario $\mathrm{N}^{\circ} 1380$ del 14 de Octubre de 1994, es el instrumento base que, junto con los antecedentes del académico y los que aporta la Comisión de su Facultad o Instituto, así como los que pueda adicionalmente recabar la Comisión Superior para mejor aplicar su experiencia, sentido común y recto juicio, permite ratificar o no al académico en la jerarquía propuesta. Dicho Reglamento establece que la evaluación académica es un proceso de análisis objetivo, en el que se consideran integradamente las aptitudes del evaluado y las actividades académicas y profesionales realizadas por éste, tanto en relación al nivel de perfeccionamiento, autonomía y reconocimiento alcanzados, cuanto al área del saber y disciplina en que el académico desarrolla o desarrollará docencia, investigación, creación artística, extensión, vinculación externa y dirección o administración académicas.

\section{Docencia, investigación y evaluación académica}

Por reconocerse, en general, que para impartir enseñanza universitaria superior se requiere no solamente conocer en profundidad la disciplina que se enseña, sino que además cultivarla, es decir, contribuir a su progreso, el Reglamento en su artículo $6^{\circ}$ impone a la calidad de académico la obligación de cumplir tanto la labor de docencia superior universitaria como la de investigación o creación artística. Para aquellos que desarrollen sólo una actividad académica y cuya dedicación horaria a la Universidad de Chile sea inferior a las 22 horas 
semanales, consulta las categorías académicas de Profesor e Instructor adjuntos.

El Reglamento de Carrera Académica, constituye el instrumento fundamental elaborado por el Consejo Universitario para promover y reconocer la excelencia académica. La Comisión Superior de Evaluación ha dedicado una significativa parte de su tiempo a promover, con la experiencia adquirida, su perfeccionamiento. Actualmente está estudiando la ampliación de las categorías adjuntas para transformarla en una Carrera Académica Alterna que, paralela a la Carrera Académica actual, permita evaluar con mayor facilidad y ecuanimidad a los académicos que sólo desempeñan docencia, otorgándoles igual relevancia y reconocimiento que a los académicos de la Carrera académica tradicional. Se dispondría así de dos vías paralelas de evaluación.

La Universidad tiene que ser un centro de trabajo científico-cultural en su doble vertiente de creación de conocimiento y de transmisión de éste. La docencia, para no caer en la inercia, debe estar ligada a la creación o investigación, así como ésta para ser perceptible y clara necesita conectarse con la enseñanza. La investigación es la condición indispensable de la ciencia, pero es un perturbador prejuicio creer que sólo hay una clase de ciencias, las experimentales, olvidando, como dice Siles, que al lado de éstas se hallan las ciencias culturales o del espíritu. Investigar no es sólo cosa de laboratorio, de análisis químico o de cálculo físico-matemático. ¡Cómo si no hubiera una ciencia de la historia, de la literatura o del derecho! ¡Cómo si no se pudiese investigar en Filosofía, en Sociología, en Pedagogía o en Arte !.

No puede haber, pues, confusión entre enseñar e investigar. En todos los territorios del saber se enseña lo que se sabe (pedagogía) y se investiga lo que no se conoce (pensamiento creativo). La docencia habitual vive, en gran medida, de las respuestas ya encontradas pero se enriquece y estimula el espíritu de su audiencia juvenil cuando las proyecta hacia las preguntas que quedan por responder. La mente creativa vive, como bien ha dicho Jorge Estrella, de las preguntas atinentes, de la visión de los problemas. La Comisión busca valorar la plena vitalidad del espíritu, esa inquietud interior de ser curioso de problemas, pero también persigue aquilatar la obra del académico en su conjunto, así como el ritmo de progreso de ésta en el tiempo.

Amar, decía nuestra Mistral, es un amargo ejercicio. Evaluar a nuestros compañeros lo es aún más. Porque si bien la verdad es una sola, los hombres le dan muchos nombres.

\section{Verdad y excelencia académica}

Tres de las más grandes conquistas de la mente humana en la historia de la humanidad han sido las religiones judeocristianas, la metafísica griega y el derecho romano. Si a estas fuentes tuviéramos que recurrir para iluminar el 
concepto de verdad que buscamos, coincidiríamos con el filósofo Julián Marías en que la verdad de cada cual puede abordarse de tres modos; como la aletheia griega, es decir, como descubrimiento de lo que es manifiesto; como la veritas latina, es decir lo que es fiel y exacto y se expone con objetividad; o como el emunah hebreo, es decir, como confianza, algo que se espera y será. Esto equivale a decir que la verdad de la labor académica puede interpretarse a través de las cosas como son, con objetividad; de las cosas como fueron o hicieron, es decir, la trayectoria académica; y de las cosas como serán, vale decir lo promisorio del académico, en el sentido profético o extrapolado. La tarea de la Comisión Superior de Evaluación se desarrolla, en su búsqueda de la verdad y de la excelencia, dentro de esta triple apreciación que nos legaran las tradiciones culturales grecolatina y judeocristiana, tan caras al espíritu universitario.

Es bueno también, al reflexionar en relación a la aproximación del ser humano que se nos pide evaluar, tener presente lo que se nos ha enseñado en el transcurso de los siglos a través de las tres importantes corrientes filosóficas a las que afluyeron, como un arroyo, el pensamiento de la mayoría de los filósofos. Bajo la luminosa y límpida luz de los cielos mediterráneos, nacería y florecería, primero con Sócrates y más tarde con Santo Tomás, la filosofía de las cosas, el realismo, la objetividad de lo que se analiza; bajo la plateada luz de los nublados cielos nórdicos se desarrollaría, con Descartes y Leibnitz, el idealismo, es decir la subjetividad de la situación que se pretende analizar; y en la meseta castellana, con Ortega y Gasset, nacería la filosofía de la razón vital y de la circunstancia que, como bien lo expresó Martín Ibáñez, conciliaba los dos sistemas anteriores y creaba un nuevo e ingenioso método de hacer frente a la vida cotidiana al considerar la circunstancia particular de la persona analizada.

Es en el seno de la Universidad donde el ejercicio del pensamiento racional, la tradición y el respeto por la persona humana, encuentran su más equilibrada confluencia y ello es garantía, para todos los académicos por igual, de que en ese espíritu serán atendidas sus solicitudes de promoción. En cada uno de los casos sometidos a su consideración la Comisión interpela a ese fondo insobornable que hay en todos nosotros. Insobornable no sólo ante el poder, el beneficio, la amistad, la indulgencia o el halago sino hasta ante el dolor personal y la incomprensión de muchos. Es el desafío de una prueba, la floración de la verdad y la equidad, que no conocen ni el prejuicio ni el temor porque ninguno de estos son nunca susceptibles de plena justificación. Si no somos sinceros y justos ¿cómo podremos serlo en todo lo demás?

No es fácil, verdaderamente, para la Comisión Superior, constituida por un conjunto de académicos de buena voluntad pero con las naturales limitaciones de todos los seres humanos, juzgar siempre con éxito absoluto y con los antecedentes puestos a su disposición por otros hombres, también falibles, la verdad completa de cada uno de los académicos sometidos a su consideración. Como en todas las empresas humanas, cabe la equivocación no intencionada. De aquí la crucial importancia de los recursos de reposición y apelación a que 
todos los académicos tienen derecho, así como las sugerencias y aportes que puedan hacernos las Comisiones de Facultades e Institutos para perfeccionar el sistema de evaluación, aunando criterios y afinándolo en expedición y equidad.

Cuando intentamos valorar la originalidad y trascendencia de las exigencias de creatividad, docencia y fidelidad a la vocación académica, verdadero yo de cada cual, lo hacemos dentro del contexto de una carrera académica, de una carrera cuyo ritmo y avance se miden en el estadio del tiempo. Pues la vida universitaria no es un estar sino un recorrer un cierto camino elegido para alcanzar la plenitud de la vocación o destino libremente elegido. $Y$ es ese recorrido en el tiempo lo que las Comisiones de Evaluación de Facultades e Institutos escrutan con tanto o más cuidado que el que dedican a considerar el volumen de la obra. Hay una especial predilección no por el que ya sabe, sino por el que quiere saber, no por la meta, sino por el camino, pues, al igual que diría Cervantes en su época: "la posada es menos interesante que el camino que a ella conduce". 